\section{Selection in energy cane families}

\section{Luís Cláudio Inácio da Silveira ${ }^{1}$, Bruno Portela Brasileiro ${ }^{2 *}$, Vol- mir Kist ${ }^{3}$, Heroldo Weber ${ }^{2}$, Edelclaiton Daros ${ }^{2}$, Luiz Alexandre Peternelli $^{3}$ and Márcio Henrique Pereira Barbosa ${ }^{1}$}

\begin{abstract}
The objective of this study was to identify superior parents for crosses and the best families to breed new clones of energy cane. The best-performing parents were RB867515, RB93509, KRAKATAU, IM76-228, IM76-229, and US851008. The heritability $(0.59-0.85)$ and accuracy values $(0.76-0.92)$ for the traits tons of cane per hectare, fiber, and sucrose content indicate high correlation between the predicted genotypic means and observed values, enabling efficient selection of the best cane energy families. The extensive genetic variation detected and the presence of promising seedlings in the selected segregating population indicate the possibility of using new crosses in some clones and even in future commercial plantings. It was possible to identify the best parents involved in the evaluated crosses, and to select, in the best families, seedlings with a high fiber and good sucrose content, seedlings with high fiber and low sugar content, as well as seedlings with the same fiber and sucrose contents as the current cultivars.
\end{abstract}

Key words: Saccharum spp., bioenergy, fiber, crop breeding.

\section{INTRODUCTION}

Sugarcane (Saccharum spp.) is one of the most efficient crops in converting solar into chemical energy (Tew and Cobill 2008). The crop is an important food and bioenergy source and a significant component of the economy in many countries in the tropics and subtropics. With the feasibility of using cane residue and bagasse in ethanol production (second generation ethanol) and with the need to increase electricity production (thermoelectricity), sugarcane became one of the main options for the energy sector, mainly because of the high biomass yield and low production cost (Dias et al. 2013).

In recent years, sugarcane breeding focused on the development of cultivars with higher sucrose yield for sugar and ethanol production (Dal-Bianco et al. 2012, Santchurn et al. 2014, laia et al. 2014, Barbosa et al. 2015, Carneiro et al. 2015). The current demand for a higher biomass volume to produce second generation ethanol and electricity generates new research lines initiated for the development of cultivars with higher fiber content, the so-called cane energy (Santchurn et al. 2014, Silveira et al. 2015a, Silveira et al. 2015b).

However, since the metabolic pathways for sucrose and fiber synthesis are antagonistic (Ming et al. 2006), cane energy cultivar should be bred from crosses between genotypes of Saccharum spontaneum and Saccharum officinarum. The reason is that $S$. spontaneum has a higher fiber content than the other species
Crop Breeding and Applied Biotechnology 16: 298-306, 2016 Brazilian Society of Plant Breeding. Printed in Brazil http://dx.doi.org/10.1590/1984$70332016 v 16 n 4 a 45$

\section{*Corresponding author: E-mail: brunobiogene@hotmail.com}

Received: 23 September 2015 Accepted: 02 August 2016

\footnotetext{
${ }^{1}$ Universidade Federal de Viçosa (UFV), Departamento de Fitotecnia, 36.570-900, Viçosa, MG, Brazil 2 Universidade Federal do Paraná (UFPR), Departamento de Fitotecnia e Fitossanitarismo, 80.035-050, Curitiba, PR, Brazil ${ }^{3}$ Instituto Federal Catarinense, 89.703-720,
} Concórdia, SC, Brazil 
of the genus Saccharum. However, their sucrose yield is low (Tew and Cobill 2008). On the other hand, the current sugarcane (Saccharum spp.) cultivars have high sucrose (>13\%) and medium fiber contents ( $13 \%)$. Thus, a combination of Saccharum spp. and Saccharum spontaneum seems ideal for the development of cane energy cultivars.

After hybridization with parents to obtain cane energy, families must be evaluated to then select individual plants within the best families, because selection in families with high genotypic values increases the probability of finding superior clones among the progenies (Barbosa et al. 2005). Based on this premise, family selection has been routinely applied prior to clone development in several breeding sugarcane programs (Stringer et al. 2011, Barbosa et al. 2012, Brasileiro et al. 2015, Silva et al. 2015).

Recently, the Rede Interuniversitária para o Desenvolvimento do Setor Sucroenergético (RIDESA - Inter-University Network for the Development of the Sugarcane Industry) initiated a hybridization program involving S. spontaneum and S. robustum accessions, cultivars of the Republic of Brazil (RB), and cultivars of other Brazilian breeding programs, for the development of clones with a fiber content above $17 \%$ and the current standard sucrose percentage of $13 \%$ in cultivars available for commercial cultivation (Silveira et al. 2015b).

As a contribution to the hybridization program and development of cane energy cultivars, the purpose of this study was to identify the best parents for future crosses, the best families for selection of individual plants and the best genotypes to be included in the next phase of the RIDESA breeding program.

\section{MATERIAL AND METHODS}

\section{Family assessment}

Fifty full-sib families from crosses performed in 2012 were evaluated at the Experimental Station of Serra do Ouro, of the Federal University of Alagoas, in the municipality of Murici (lat 9o 13' S, long 35 50' W, and alt 450m asl), Alagoas, Brazil. After harvesting, seeds derived from biparental crosses were sent to the Experimental Station of Paranavaí of the Federal University of Paraná, in Paranavaí (lat 230 05' S, long 52 $27^{\prime} \mathrm{W}$, and alt $503 \mathrm{~m}$ asl), Paraná, Brazil, where they were sown in LVD soil. In October 2012, when grown to seedlings, the experiment was installed in a randomized block design with five replications. Each plot consisted of 20 seedlings, distributed in two $8 \mathrm{~m}$ long rows, spaced $1.40 \mathrm{~m}$ apart. The ratoon data were collected in July 2014, 11 months after the first cut.

The traits evaluated in families at the plot level were: mean number of stalks per plant (NS); mean stalk weight (MSW) estimated from the mean weight of 20 stalks per plot; fiber content in percent (FIB\%) and sucrose content (SC\%). The fiber and sucrose contents were determined in analyses of $500 \mathrm{~g}$ samples of flour of 10 ground stalks, in 2 replications per family. In this way, we determined tons of cane per hectare, by weighing five replications (TCH. $5 r$ ): TCH. $5 r=$ (NS $\times$ $\mathrm{mSW} \times 10) / 1.12$, where: 1.12 = area occupied per plant in a plot in $\mathrm{m}^{2}$ and 10 is the constant used to convert weight per plot into tons per hectare.

From the mean fiber content (FIB\%), sucrose content (SC\%) and tons of cane or stalks per hectare, in two experimental replications (TCH.2r), it was also possible to estimate the tons of fiber per hectare (TFH): TFH $=(\mathrm{TCH} .2 \mathrm{r} \times \mathrm{FIB} \%) / 100$ and tons of sucrose per hectare $(\mathrm{TSH}): \mathrm{TSH}=(\mathrm{TCH} .2 \mathrm{r} \times \mathrm{SC} \%) / 100$.

To analyze the data of TCH.5r, TCH.2r, FIB\%, SC\%, TFH, and TSH we used the following statistical model: $y=\mathrm{Xr}+\mathrm{Zg}$ $+e$, where: $y=$ data vector $(y \sim N(X r, V)) ; r$ is the vector of replication effects (assumed as fixed), added to the overall mean; $g$ is the vector of genotypic effects, $g \sim N(0, G), G=$ covariance matrix of genotypes $\left(G=I \sigma_{g}^{2}\right)$; e is the error vector, where: $\mathrm{e} \sim \mathrm{N}(0, \mathrm{R}), \mathrm{R}=$ residual covariance matrix $\left(\mathrm{R}=\mathrm{I} \sigma_{e}^{2}\right)$. $\mathrm{X}$ and $\mathrm{Z}$ are the incidence matrices for these effects. The variance components $\sigma_{g}^{2}$ and $\sigma_{e}^{2}$ are the genetic and residual variance, respectively. Mixed model analysis REML/BLUP was performed using SELEGEN software (Resende 2007).

\section{Clone selection and evaluation}

The 10 best families were selected for the main yield-related traits in sugarcane (tons of cane and fiber and sucrose contents per hectare. Within each family, the target was to select at least $10 \%$ of the genotypes, i.e., 10 seedlings per family. 
The selected seedlings were technically analyzed to establish estimates of the traits purity percentage (PUR\%), percentage sucrose content (SC\%), fiber content in percent (FIB\%) and total recoverable sugar in $\mathrm{kg}$ of sugar per tons of cane (TRS).

\section{RESULTS AND DISCUSSION}

The genetic and environmental parameters resulting from the evaluation of 50 full-sib families by the REML/BLUP method are shown in Table 1. The significant effect of genetic variance indicates the existence of genetic variability in the evaluated families and reinforces the possibility of genetic gains by selection (Table 1).

The mean family heritability $\left(h^{2}\right)$ was high for the traits FIB\%, SC\% and TCH.5r, which allowed selection of the best families, with accuracy higher than $76 \%$, suggesting a high correlation between the predicted and actual mean genotypic values of the evaluated families, which indicates the possibility of genetic gain with selection of the best families (Table 1).

For TFH and TSH, $h^{2}$ was low due to the lower number of replications used in the estimates of the means of these traits (Table 1). With only two replications, heritability is greatly reduced and consequently, the accuracy in estimating the genotypic means of the trait tons of cane per hectare ( $\mathrm{TCH} .2 \mathrm{r}$ ). Since the technological analyses were carried out in only two replications, only the cane yield data of the same plots could be used to estimate the genetic parameters of the traits TFH and TSH, which is exactly what contributed to the low heritability of these traits (Table 1). However, in the estimates of genotypic means of FIB\% and SC\%, accuracies above $90 \%$ were obtained with only two replications, indicating that these traits were barely influenced by environmental effects.

In the evaluation of experimental traits, the accuracy of the coefficients of variation (CV\%) was good (Table 1). The effects of genotypic variance were significant by Deviance analysis, indicating the presence of genetic variability among the evaluated families (Table 1).

Since the heritability for FIB\%, SC\% and TCH.5r was higher than heritability for tons of fiber per hectare (TFH) and tons of sucrose per hectare (TSH) (Table 1), the families were ranked for the traits TFH and TSH based on the genotypic means of FIB\% and SC\%, together with the genotypic mean of $\mathrm{TCH} .5 \mathrm{r}$.

After ranking the families, the best 10 for TCH.5r, TFH and TSH were selected, followed by the selection of 3 to $17 \%$ of the seedlings in the best families, resulting in a total of 199 plants selected from 22 families (Table 2).

With the exploitation of the best families, possibly a higher number of high-yielding clones can be included in the subsequent steps of a sugarcane breeding programs (Barbosa et al. 2005, Brasileiro et al. 2015). Therefore, the identification of promising parents for crosses is essential to accelerate genetic gains and increase the likelihood of identification and selection of transgressive genotypes.

The families with highest means for tons of fiber per hectare (TFH) were 36 (IM76-228 × RB867515) and 46 (RB867515 $\times$ IM76-228). These families were outstanding for having a high fiber content (>14\%) along with a high biomass yield, as well as the highest mean for tons of cane per hectare (TCH.5r) (Table 2 and Figure 1a).

Table 1. Estimates of genetic and environmental parameters of 50 full-sib families of the sugarcane

\begin{tabular}{lcccccc}
\hline \multirow{2}{*}{ Parameters $^{\mathrm{a}}$} & \multicolumn{5}{c}{ Traits } \\
\cline { 2 - 6 } & FIB\% & SC\% & TCH.5r & TCH.2r & TFH \\
\hline$\hat{\sigma}^{2}$ & $1.83^{*}$ & $4.99^{*}$ & $431.33^{*}$ & $190.39^{*}$ & $10.41^{*}$ & $1.80^{*}$ \\
$h_{g}^{2}$ & $0.75+-0.24$ & $0.72+-0.24$ & $0.32+-0.13$ & $0.09+-0.08$ & $0.23+-0.13$ \\
$h^{2}$ & 0.85 & 0.84 & 0.59 & 0.16 & $0.05+-0.06$ \\
Accuracy & 0.92 & 0.91 & 0.76 & 0.40 & 0.38 & 0.62 \\
$r$ & 2 & 2 & 5 & 2 & 2 & 0.10 \\
CV\% & 5.95 & 12.00 & 31.86 & 32.74 & 33.30 & 36.72 \\
Mean & 12.99 & 11.35 & 121.43 & 132.72 & 17.33 \\
\hline
\end{tabular}

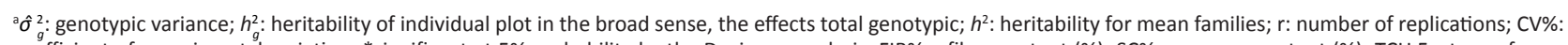

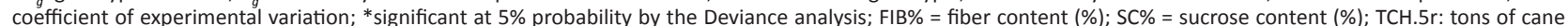

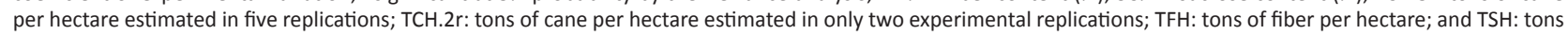
of sucrose per hectare. 
Table 2. Genotypic means of the traits sucrose content (SC\%), fiber content (FIB\%), tons of cane per hectare in five replications (TCH.5r), tons of fiber per hectare (TFH), tons of sucrose per hectare (TSH), and number of seedlings selected ( $\left.n_{k}\right)$ in the 22 best families

\begin{tabular}{|c|c|c|c|c|c|c|c|c|c|}
\hline \multirow{2}{*}{ Family } & \multicolumn{2}{|c|}{ Pedigree } & \multicolumn{5}{|c|}{ Traits } & & \multirow[b]{2}{*}{$n_{k}$} \\
\hline & Mother & Father & SC\% & FIB\% & TCH.5r & TFH & TSH & & \\
\hline 1 & RB011941 $^{b}$ & US85-1008 ${ }^{b}$ & 12.37 & 12.54 & 125.75 & 15.77 & 15.56 & & 10 \\
\hline 3 & $\mathrm{~B} 70710^{\mathrm{b}}$ & RB72910 & 8.87 & 12.45 & 142.34 & 17.72 & 12.62 & & 4 \\
\hline 5 & Co62175 & IANE48-21 ${ }^{\mathrm{b}}$ & 12.41 & 11.04 & 124.56 & 13.75 & 15.46 & & 9 \\
\hline 6 & IAC87-3396 & US85-1008 & 12.94 & 13.43 & 133.14 & 17.88 & 17.23 & & 5 \\
\hline 10 & B70710 b & RB93509a & 8.75 & 11.85 & 139.96 & 16.58 & 12.25 & & 11 \\
\hline 16 & RB01649a & IN84-58 & 9.23 & 16.04 & 115.62 & 18.55 & 10.68 & & 9 \\
\hline 22 & RB867515 a & US85-1008 & 11.69 & 13.66 & 139.8 & 19.09 & 16.34 & & 10 \\
\hline 24 & RB92579a & IM76-229 & 9.47 & 14.24 & 142.04 & 20.22 & 13.45 & & 9 \\
\hline 27 & RB93509a & $\mathrm{Co} 285^{\mathrm{b}}$ & 11.77 & 12.63 & 128.57 & 16.24 & 15.14 & & 17 \\
\hline 30 & $\mathrm{CTC5}^{\mathrm{a}}$ & US85-1008 & 13.23 & 13.28 & 121.54 & 16.15 & 16.08 & & 3 \\
\hline 40 & IM76-228 & US85-1008 & 9.38 & 14.65 & 133.35 & 19.54 & 12.51 & & 8 \\
\hline 41 & $\mathrm{~F} 150^{\mathrm{b}}$ & IN84-68 & 9.46 & 15.39 & 122.45 & 18.84 & 11.59 & & 8 \\
\hline 43 & RB867515 & US76-14? & 12.31 & 12.97 & 141.77 & 18.39 & 17.45 & & 10 \\
\hline 44 & RB93509a & B70710 & 10.64 & 11.53 & 139.21 & 16.05 & 14.81 & & 17 \\
\hline 45 & СТC9 & UM69/001? & 13.03 & 12.34 & 133.4 & 16.46 & 17.38 & & 8 \\
\hline 46 & RB867515a & IM76-228 & 9.11 & 14.38 & 158.76 & 22.82 & 14.46 & & 10 \\
\hline \multirow[t]{2}{*}{48} & RB946022 $^{\mathrm{a}}$ & RB92579a & 14.48 & 11.85 & 119.67 & 14.19 & 17.33 & & 10 \\
\hline & \multicolumn{2}{|c|}{ Mean } & 10.71 & 13.41 & 134.29 & 18.08 & 14.22 & Total & 199 \\
\hline
\end{tabular}

a Saccharum spp., baccharum spontaneum, ' Saccharum robustum, ? unknown parents.

The families 36 and 46 are reciprocal crosses between IM76-228 and RB867515. It shows the potential of combining these two parents to obtain energy cane cultivars, since their descendants have the vigor and productivity of RB867515, the cultivar most widely planted in the world (on nearly 3 million hectares in Brazil alone), associated with the high fiber content of IM76-228, a parent descendant of Saccharum robustum, whose great potential to obtain cane energy cultivars was observed in crosses.

Other families with high TFH means were 34 (RB93509 × KRAKATAU), 11 (RB83102 × IM76-229), 24 (RB92579 × IM76229), 13 (Co617 × KRAKATAU), 40 (IM76-228 × US85- 1008), and 22 (RB867515 × US85-1008). This also demonstrated the potential of the parents KRAKATAU, IM76-229 and US85-1008 for breeding of cane energy cultivars, in view of their high fiber content and biomass production in more than one cross (Table 2). These parents should be explored in hybridizations with other parents of the breeding program of RIDESA (RB cultivars) as a way of optimizing the development process of cane energy cultivars. Furthermore, hybridization between these parents can contribute to intrapopulation improvement, since these genotypes belong to the same heterotic group.

Family 16 (RB01649 × IN84-58) had the highest mean for fiber content (FIB\%) (Table 2 and Figure 1a), which may be a consequence of the genes transmitted by parent IN84-58. Therefore, new hybridizations between this parent and Saccharum spp. parents should be explored in order to assess the potential of this parent for the development of cane energy cultivars.

Outstanding performances were also observed in family 27 (RB93509 $\times$ Co285) and 44 (RB93509 $\times$ B70710). A large number of seedlings were selected $\left(n_{k}=17\right)$ from these families, exceeding the target $\left(n_{k}=10\right)$ during visual selection performed in the best families (Table 2).

In some families, the selection rate $\left(n_{k}=10\right)$ was not met, e.g., for family 30 (CTC5 $\times$ US85-1008), 6 (IAC87-3396 $\times$ US85-1008) and 3 (B70710 $\times$ RB72910) (Table 2). In these families, the high incidence of diseases such as smut 

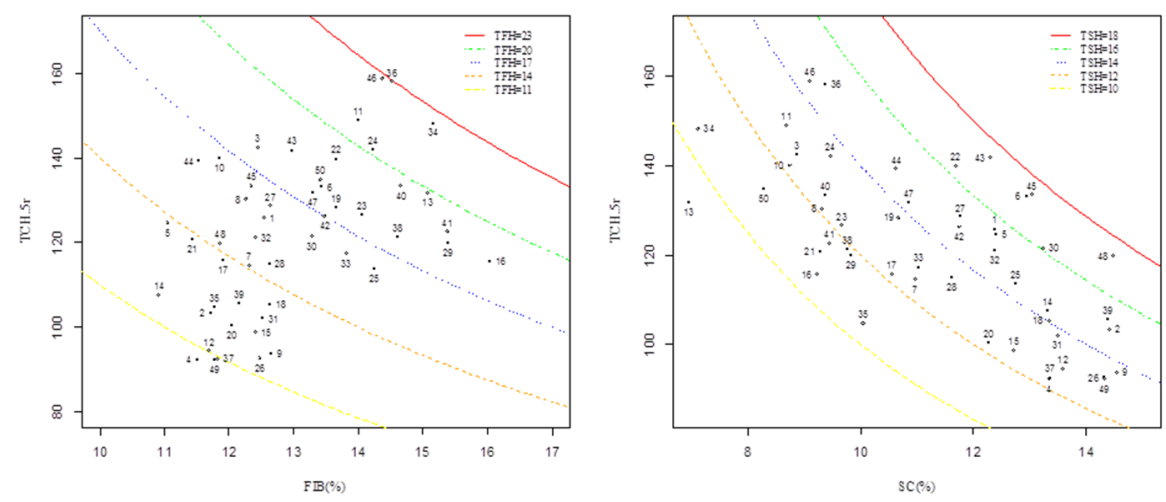

Figure 1. a) Isoquants of tons of fiber per hectare (TFH) inferred from the genotypic means of fiber content (FIB\%) and tons of cane per hectare (TCH.5r) of 50 energy cane families and b) isoquants of tons of sucrose per hectare (TSH) obtained with the genotypic means of the sucrose content (SC\%) and ton of cane per hectare (TCH.5r) of 50 energy cane families.

(Sporisorium scitamineum) and orange rust (Puccinia kuehnii), together with the reduced seedling vigor, resulted in the low selection rate.

The best performances in sucrose yield were observed in the families 43 (RB867515 × US76-14), 45 (CTC9 × UM69/001), 48 (RB946022 × RB92579), and 6 (IAC87-3396 × US85-1008), with sucrose yields of up to 17 tons per hectare (Table 2 and Figure $1 \mathrm{~b})$.

The SC was highest in family 48, which actually involved a cross between two parents, both descendants of Saccharum spp. This cross maintained the high sucrose content of conventional crosses but had one of the lowest fiber contents (Table 2). This result was expected, since both parents have low fiber content.

The reason to select families with high genotypic mean for TFH and TSH was mainly the maintenance of genetic variability in the second test phase (T2) of the breeding program. Thus, an advancement of clones with high fiber content during the next stages of selection is expected, in addition to the selection of clones with the industrial traits found in the current cultivars. On this basis, future parents for backcross programs can be selected, and in a more optimistic scenario, it is possible to expect the release of new cultivars of cane energy and/or conventional sugarcane, since there are promising clones among the selected.

Table 3 shows the fiber content (FIB\%), sucrose content (SC\%), purity (PUR\%) and total recoverable sugar (TRS) of 35 of 199 of selected clones, which have industrial characteristics of energy cane.

The 35 most promising seedlings have a high fiber content and many of them also a high sucrose content. The description and agronomic evaluation of all clones during the following stages of the breeding program can confirm the potential of each selected genotype. Some of these clones may result in the first energy cane cultivars type 1, as described by Tew and Cobill (2008), with higher fiber and the current mean sucrose contents.

Among the 35 promising genotypes, 24 were selected from families with high mean FIB\% and reduced mean SC\%. These families were $11,13,16,24,36,40,41$, and 46 . The performance of these families for SC\% and FIB\% can be

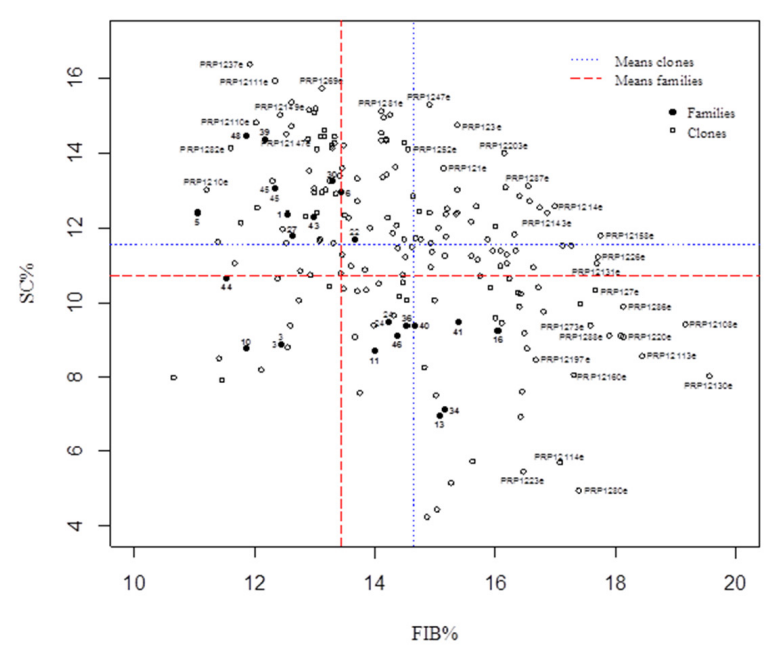

Figure 2. Dispersion of selected seedlings and of the 22 best families from the traits sucrose content (SC\%) and fiber content (FIB\%). 
observed in Figure 1b. In family 36, with highest TFH (Table 2 and Figure 1b), 5 of 10 selected seedlings were among the 35 most promising genotypes, demonstrating once again the potential of the combination between the parents IM76-228 and RB867515.

As seen in Figure 2, there is broad genetic variability for SC\% and FIB\% both among families and among selected plants, demonstrating that the selection strategy was effective in maintaining the variability to be explored in the second selection stage.

By the selection strategy used here, it was possible to increase the probability of selecting seedlings with specific traits, such as the genotypes PRP1280e, PRP12108e, and PRP12130e, with fiber contents between $17.38 \%$ and $19.55 \%$ and low sucrose content, as well as genotypes with fiber content of over $15 \%$, but also with high sucrose content,

Table 3. Means of fiber content (FIB\%), sucrose content (SC\%), purity (PUR\%) and total recoverable sugar (TRS) and the origin (family) of 35 promising genotypes

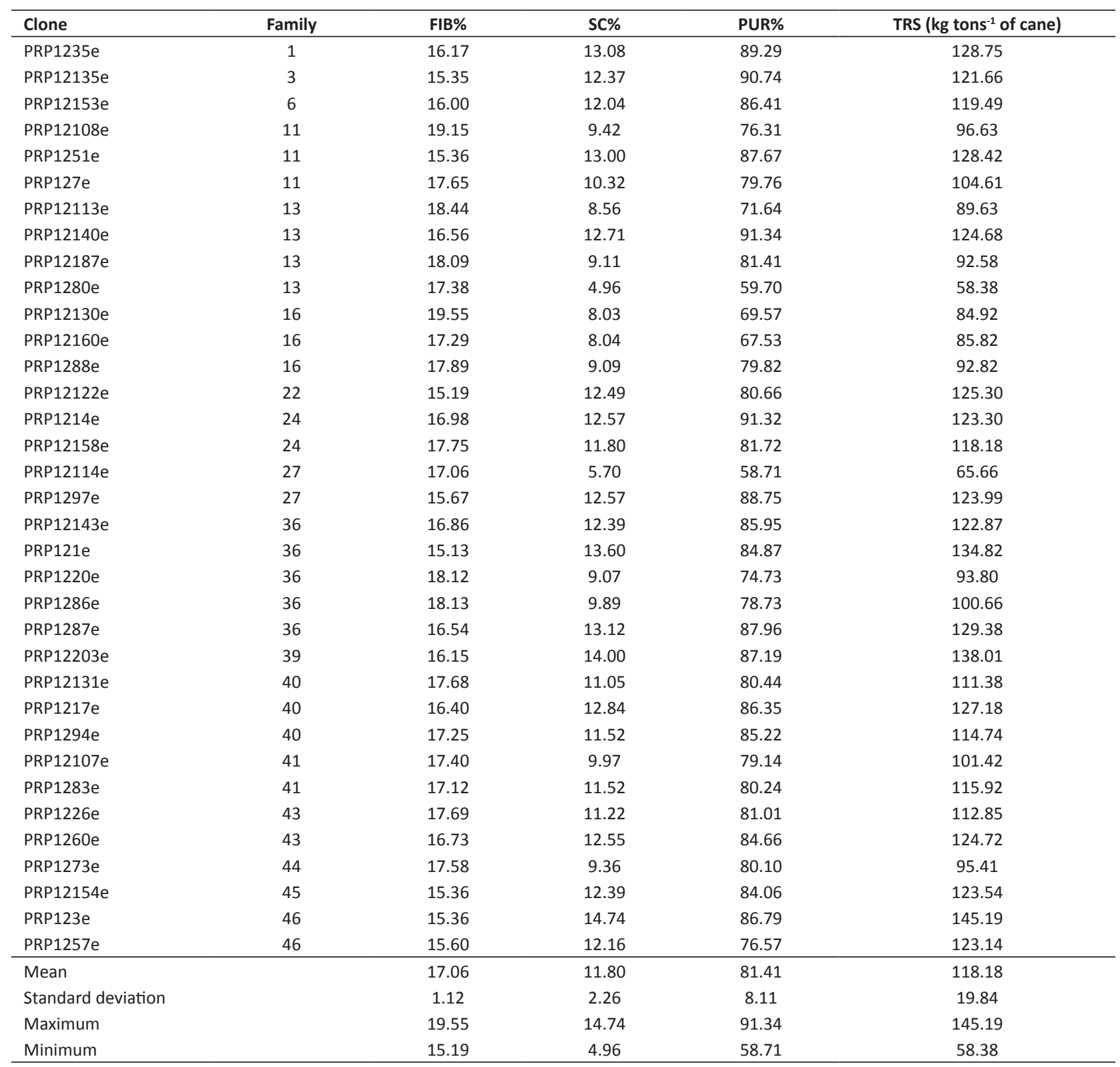




\section{LCl Silveira et al.}

similarly to PRP12158e, PRP1214e, PRP12203e, PRP1260e, and PRP123e, aside from other genotypes that also had higher means of SC\% and/or FIB\% than the selected clones (Figure 2).

In the breeding program of Barbados, clones with up to $42 \%$ fiber content and a Brix content of $23.5 \%$ were obtained by crossing parents originating from recurrent selection with $S$. spontaneum accessions to increase sucrose contents (Kennedy 2008). Santchurn et al. (2014) also obtained four types of high biomass genotypes in the Mauritius Sugarcane Industry Research Institute. The results obtained in Barbados, Mauritius, as well as in this study showed that the broad genetic variability in the Saccharum complex can be exploited for different purposes, in view of the numerous possibilities for new gene rearrangements in sugarcane, which will allow radical changes in the traits of future cultivar.

The selected genotypes have great potential to be exploited commercially and also in future crosses. Importantly, although these clones have interesting industrial traits, they must have high biomass productivity, be tolerant to the major pests and diseases, have longevity of the ratoon crop. Therefore, these traits should also be evaluated in the next selection stages.

The selection of sugarcane parents and hybrid combinations should be based on data of genetic diversity and the inbreeding coefficient to fully exploit the effects of dominance in hybridizations between parents of different heterotic groups (Brasileiro et al. 2014). The adequate choice of the parents and combinations between them has contributed to the development of new cultivars, such as the large number of cultivars developed from hybridizations of RB72454 and SP70-1143. The crosses involving these two parents resulted in 10 cultivars, including the most commonly cultivated and planted in Brazil (Daros et al. 2015). In fact, specific combinations are able to raise heterosis in segregating generations and increase the chances of identifying transgressive clones in their progenies (Silveira et al. 2015a).

Hybrid combinations should be indicated based on the potential per se of the parents and the magnitude of their dissimilarities. The findings of this study may be highly useful in the development of new crosses involving parents with higher fiber content, which are mainly descendants of S. spontaneum and S. robustum with current clones and cultivars (Saccharum spp.).

Breeders have thoroughly explored the high sucrose potential in the sugarcane breeding programs. However, due to difficulties in recent years in obtaining genetic gain for this trait (Dal-Bianco et al. 2012), apart from the growing worldwide demand for renewable energy, an alternative for the sugar-energy industry would be the development of cultivars with higher biomass production capacity and high fiber content. These new cultivars can significantly increase energy cogeneration, and optimize the exploitation of cellulose and hemicellulose, both in the production of second generation ethanol as of bio-oil and other products from biomass pyrolysis (Yang et al. 2006).

According to Tew and Cobill (2008), currently grown sugarcane contains around $12 \%$ fiber and $13 \%$ sugar. According to these authors, the target of breeding cane energy cultivars should be $30 \%$ fiber and $5 \%$ sugar. But the way to achieve genotypes with these characteristics is still very long. Nowadays, energy plants are not able to process sugarcane with more than $20 \%$ fiber content. In this case, to meet the present demand of the sugarcane industry, cultivars with contents of fiber around $17 \%$ and sucrose of $13 \%$ are needed. This increase in fiber content would be interesting from an industrial point of view, once the sugar yield would be maintained and quality of the bagasse used in power cogeneration would be better and the calorific value consequently higher, allowing higher electricity production per ton of processed waste.

Reciprocal recurrent selection (RRS) should be applied based on the pedigree information and genetic diversity in order to exploit the heterosis of future crosses as much as possible. The potential of RRS to obtain vigorous hybrids is considerable. Therefore, the populations of Saccharum spontaneum, Saccharum robustum and Saccharum spp. must be improved by intra and interspecific hybridizations of the best parents of each population and recombinant generation.

Increasing the fiber content via recurrent selection in S. spontaneum and S. robustum populations is essential for the success of the cane energy program, since the use of parents with fiber levels superior to those used in the 50 crosses evaluated in this study can generate plants with fiber levels higher than those selected to date.

The findings of this study are essential as orientation for new hybridizations and to develop new evaluation and selection strategies for cane energy families. Crosses between Saccharum spp. $\times$ Saccharum spontaneum and Saccharum spp. $\times$ Saccharum robustum should be heavily exploited, with a view to increasing the current fiber content in future cultivars 
(Ming et al. 2006). In addition, due to the expansion of sugarcane cultivation in Brazil in recent years, especially in areas with soil and climatic constraints, crosses of current cultivars with descendants of S. spontaneum and S. robustum can also contribute to the introgression of alleles responsible for providing increased longevity of sugarcane with mechanical planting and harvesting, as well as alleles with higher tillering capacity and also for tolerance of the major pests and diseases, aside from other biotic and abiotic stresses occurring in sugarcane.

\section{CONCLUSION}

The best parents in the development of clones with high fiber productivity are RB867515, RB93509, RB92579, KRAKATAU, IM76-228, IM76-229, and US85-1008. It was also possible to identify and select seedlings of the best families with a high fiber content combined with good sucrose content, seedlings with fiber content close to $20 \%$ and a low sucrose content, as well as seedlings with the same fiber and sucrose contents as the currently planted cultivars.

\section{ACKNOWLEDGEMENTS}

The authors are indebted to the Coordination of Improvement of Higher Education Personnel (CAPES), and the National Research Council (CNPq) for financial support.

\section{REFERENCES}

Barbosa GVS, Oliveira RA, Cruz MM, Santos JM, Silva PP, Viveiros AJA, Sousa AJR, Ribeiro CAG, Soares L, Teodoro I, Sampaio Filho F, Diniz CA and Torres VLD (2015) RB99395: Sugarcane cultivar with high sucrose contente. Crop Breeding and Applied Biotechnology 15: 187-190.

Barbosa MHP, Resende MDV, Bressiani JA, Silveira LCl and Peternelli LA (2005) Selection of sugarcane families and parents by REML/BLUP. Crop Breeding and Applied Biotechnology 5: 443-450.

Barbosa MHP, Resende MDV, Dias LAS, Barbosa GVS, Oliveira RA, Peternelli LA and Daros E (2012) Genetic improvement of sugarcane for bioenergy: the Brazilian experience in network research with RIDESA. Crop Breeding and Applied Biotechnology S12: 87-98.

Brasileiro BP, Marinho CD, Costa PMA, Cruz CD, Peternelli LA and Barbosa MHP (2015) Selection in sugarcane families with artificial neural networks. Crop Breeding and Applied Biotechnology 15: 72-78.

Brasileiro BP, Marinho CD, Costa PMA, Moreira EFA, Peternelli LA and Barbosa MHP (2014) Genetic diversity in sugarcane varieties in Brazil based on the Ward-modified location model clustering strategy. Genetics and Molecular Research 13: 1650-1660.

Carneiro MS, Chapola RG, Fernandes Júnior AR, Cursi DE, Barreto FZ, Balsalobre TWA and Hoffmann HP (2015) RB975952 - Early maturing sugarcane cultivar. Crop Breeding and Applied Biotechnology 15: 193-196.

Dal-Bianco M, Carneiro MS, Hotta CT, Chapola RG, Hoffmann HP, Garcia AAF and Souza GM (2012) Sugarcane improvement: How far can we go? Current Opinion in Biotechnology 23: 265-270.

Daros E, Oliveira RA and Barbosa GVS (2015) 45 anos de variedades RB de cana-de-açúcar: 25 anos de Ridesa. Graciosa, Curitiba, 156p.

Dias MOS, Junqueira TL, Cavalett O, Cunha MP, Jesus CDF, Mantelatto PE, Rossell CEV, Maciel Filho R and Bonomi A (2013) Cogeneration in integrated first and second generation ethanol from sugarcane. Chemical Engineering Research and Design 91: 411-1417.
Kennedy AJ (2008) Prospects for combining high sucrose content with increased fibre to generate multi-purpose cane varieties. http:// www.jamaicasugar.org/wist/Proceedings/Prospects $\% 20$ for $\% 20$ combining\%20high\%20sucrose\%20content.pdf

laia AM, Oliveira RA, Melo LJOT, Daros E, Simões Neto DE, Bastos GQ, Oliveira FJ, Chaves A and Melo TTAT (2014) RB002504 - New early-maturing sugarcane cultivar. Crop Breeding and Applied Biotechnology 14: 45-47.

Ming R, Moore PH, D'Hont A, Glaszmann JC, Tew TL, Mirkov TE, Silva J, Jifon J, Rai M, Schell RJ, Brumbley SM, Lakshmanan P, Comstock JC and Paterson AH (2006) Sugarcane Improvement through Breeding and Biotechnology. In Janick J (ed) Plant breeding reviews. John Wiley, New York, p. 15-118.

Resende MDV (2007) Software SELEGEN-REML/BLUP: sistema estatístico e seleção genética computadorizada via modelos lineares mistos. Embrapa Florestas, Colombo, 359p.

Santchurn D, Ramdoyal K, Badaloo MGH and Labuschagne M (2014) From sugar industry to cane industry: Evaluation and simultaneous selection of different types of high biomass canes. Biomass and Bioenergy 61: 82-92.

Silva FL, Barbosa MHP, Resende MDV, Peternelli LA and Pedrozo CA (2015) Efficiency of selection within sugarcane families via simulated individual BLUP. Crop Breeding and Applied Biotechnology 15: 1-9.

Silveira LCI, Brasileiro BP, Kist V, Daros E and Peternelli LA (2015a) Genetic diversity and coefficient of kinship among potential genitors for obtaining cultivars of energy cane. Revista Ciência Agronômica 46: 358-368.

Silveira LCl, Brasileiro BP, Kist V, Daros E, Peternelli LA and Barbosa MHP (2015b) Selection strategy in families of energy cane based on biomass production and quality traits. Euphytica 201: 443-455.

Stringer JK, Cox MC, Atkin FC, Wei X and Hogarth DM (2011) Family selection improves the efficiency and effectiveness of selecting 


\section{LCI Silveira et al.}

original seedlings and parents. Sugar Tech 13: 36-41.

Tew TL and Cobill RM (2008) Genetic improvement of sugarcane (Saccharum spp.) as an energy crop. In Vermerris W (ed) Genetic improvement of bioenergy crops. Springer, New York, p. 273-294.
Yang H, Yan R, Chen H, Zheng C, Lee DH and Liang DT (2006) In-Depth investigation of biomass pyrolysis based on three major components: hemicellulose, cellulose and lignin. Energy Fuels 20: 388-393. 